\title{
Do indivíduo de referência ao consumo visual e o gesto da arte na fotografia de identificação
}

\section{From the individual of reference to visual consumption and the gesture of art in identification photography}

Rafael Tassi Teixeira ${ }^{1}$

Resumo: Este trabalho tenta observar a construção da potência fotográfica em uma fotografia icônica realizada por Wilhem Brasse em 1940. Fotógrafo prisioneiro em Auschwitz durante os anos de 1940-1944, Brasse realizou mais de 45 mil fotos em estilo de identificação. Na foto de Jan Komski, o trabalho de posado e a figurabilidade enfrentam uma dialética do testemunho que se mantém em espera de um contraplano melhor, futuro. Trabalha-se aqui com a relacionalidade da foto em um duplo aspecto: $o$ ato de impor à imagem uma tentativa de sujeição ao holótipo negativo e o trabalho do fotógrafo em condições extremas. O artigo conclui que a reinscrição artística e o consumo visual enlaçam a fotografia, 70 anos depois, em uma tentativa de premir uma ética da arte e uma estésica do episódio.

Palavras-chave: fotografia; consumo visual; memória; Wilhem Brasse.

Abstract: This work tries to observe the construction of the photographic power in an iconic picture realized by Wilhem Brasse in 1940. Priosioner Photographer in Auschwitz during the years 1940-1944, Brasse took more than 45,000 photos in identification style. In Jan Komski's photo, the work of posture and figurability face a dialectic of testimony that stands in wait for a better, future counter-plan. We work here with the relationality of the photo in a double aspect: the act of imposing on the image an attempt to subjection to the negative holotype, and the

1 Universidade Tuiuti do Paraná (UTP). Curitiba, PR, Brasil.

https://orcid.org/0000-0001-7137-0904. E-mail: rafatassiteixeira@hotmail.com 
work of the photographer in extreme conditions. The article concludes that artistic reinscription and visual consumption entwine the photograph, seventy years later, in an attempt to press an art ethic and an aesthetic of the episode.

Key-words: photography; visual consumption; memory; Wilhem Brasse. 


\section{Introdução: sobre o sistema redutor e as fotos}

O registro, por si só, hostilizava: logo ao chegar, com a roupa imunda que era recebida de alguém que já morrera. A fotografia impunha uma espécie de submissão do fotografado ao castigo da imagem, designando um lugar de sujeição holotípica. ${ }^{2}$ Isto é, receber sua destemporalização através da substituição do nome por um número, olhar a construção da cena em silêncio, ser olhado como um objeto inerte. As imagens transformariam, dessa forma, o rosto em uma arquetipologia raciológica. Pura carcaça, a face representava a brutalidade da cena exposta. As sessões eram concebidas, segundo Zelizer (1998), dentro de um programa que, ao mesmo tempo, pressupunha a identificação estrutural e a valorização no esquema about-to-die. ${ }^{3}$ Eram pretendidas para a marcação tipológica e a violência do ato despedaçava ainda mais a vítima: seu rosto era atado como um símbolo da memória racial que deveria ser, na lógica infame do sistema nazi, individualmente apagada.

Multiplicados à exaustão na obsessividade pela uniformização dos nazistas (foram realizadas mais de 45 mil fotos), os registros tinham, portanto, de ser feitos com instruções que designavam a lógica do sistema redutor: a construção da diferença concebida como pura negatividade, pura despersonalização, pura infâmia. Nesse sentido, a retórica racial, no âmbito da imagem tipológica e holotípica, era assumida diante da pretensão de escrever um núcleo, lido como deforme, da perspectiva da alteridade. Em fotos realizadas uma única vez para poupar negativo (ENGELMANN, 2015), o esquema de três séries (lateral, frontal,

2 Processo de "referencialidade constitutiva" que, na linguagem taxológica, designa a espécie-tipo que serve de unidade visual para a descrição de um taxon; colocado no âmbito da antropologia, inscreve o processo de arquetipização do indivíduo de referência, bastante usado na antiga antropologia física do final do século XIX (RASSOOL e HAYES, 2001) e nas relações entre fotografia, fenótipo e antropometria (EDWARDS, 2004); no caso da raciologia nazi (ZELIZER, 1998), o indivíduo de referência era marcado pela justaposição entre raça, fenomenologia e negatividade.

3 Imagens, segundo Sanchez-Biosca (2017), realizadas “à beira da morte”, geralmente produzidas pelos perpetradores, em uma relação indissociável entre a violência física e psicológica e o ato de registro. Estão nessa classe de imagens, por exemplo, as fotos dos militares norte-americanos em Abu Gharib, as fotografias feitas pelos regime do Khmer Vermelho no Camboja e as fotografias produzidas pelos oficiais nazistas durante a Segunda Guerra. 
rosto virado para o lado) estava baseado em uma hierarquia da memória raciológica. ${ }^{4}$

Figura 1: imagem de prisioneiro em Auschwitz

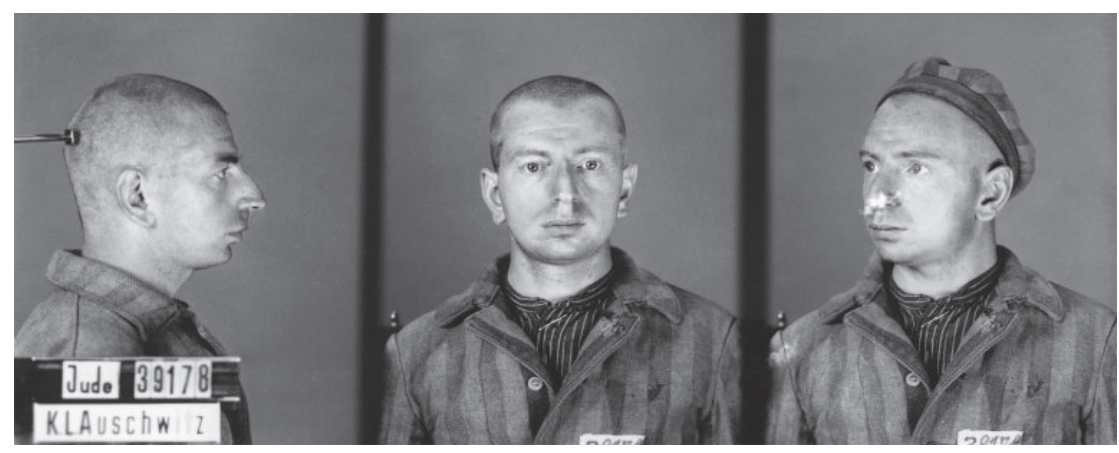

Nessas séries fotográficas, a funcionalidade latente do esquema reservava para a descontextualização biográfica da foto uma redundância escopofílica. Quase sempre com a mesma disposição: instrução para o posar dentro de um modelo de registro criminal, mínimas condições de luz, precariedade da imagem no vazio do fundo visual, expressão normalmente contida e sem expor admoestação. Ou seja, a fotografia era, ao mesmo tempo, reprodução de um projeto e duração de um preconceito. Alimentava-se das descrições fenotípicas como se quisesse fazer onipresente a forma fotográfica e a indubitável relação entre ciência e espetáculo. 5

Emanação de uma estética da periculosidade, a foto revelava a perfectibilidade negativa. Isto é, ao se assignar o lugar de uma cópia (infame) sobre a posição seriada, a fotografia tinha de ser uma constatação voluntariosa do corpo, do rosto, dos elementos composicionais definidos

4 Um "atlas" warburgiano feito a partir da decadência; semelhanças gradativas realizadas com uma intenção de transmissão de uma espécie de pathos negativo, repleto de "amostras" lidas como biologicamente ruins.

5 A compulsiva circulação dos padrões antropométricos e sua demonstrabilidade na relação com a fotografia. Baseando-se, sobretudo, em uma hiperfocalização dos traços faciais em uma ocularização testemunhal. 
em seu potencial patológico: a indelével composição prefigurada que marcaria a imagem para sempre. ${ }^{6}$

Ao ser inserido numa espécie de esquema essencial, o retrato era intensamente reduzido à coisificação laudatória - uma insuficiência nominal, uma reapropriação do vestígio iconográfico na história antropológica. Impregnado de contextualização criminosa, o testemunho, aqui, queria cicatrizar a "perfectibilidade negativa" em um rosto constantemente variável, mas assigne, idealizado, culposo.

Um rosto, sobretudo, onde o eludido, o indefectível, o abjeto constroem uma relação direta com a ciência métrica e racial.

Figura 2: Jan Komski em Auschwitz

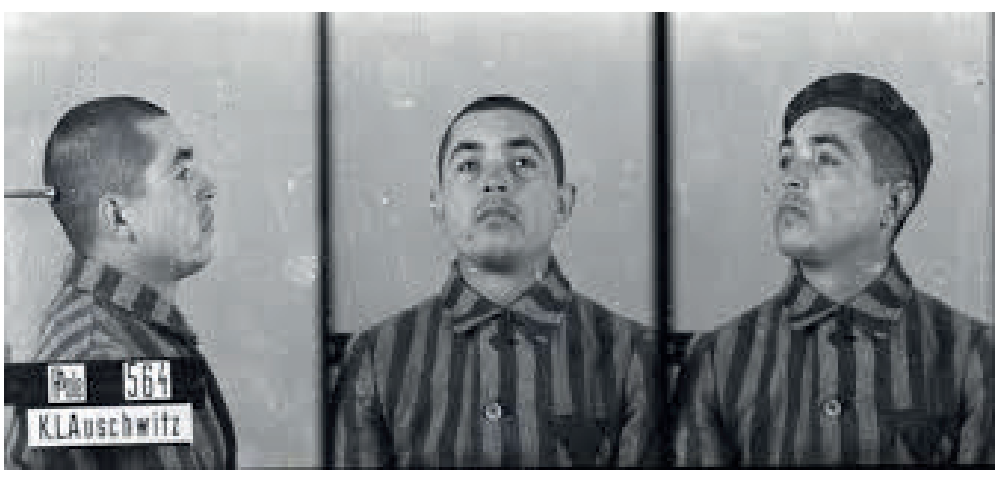

Na fotografia de Komski, ${ }^{7}$ realizada por Wilhem Brasse em 1940, a sequencialidade do programa das três imagens é observada de forma semelhante ao registro de Czeslawa, estabelecendo arquetipicamente

6 Isto é, a "perfectibilidade negativa" no esteio de uma redução plástica do rosto ao arquétipo racial.

7 Preso em 1940 na fronteira da Tchecoslováquia após fugir da Polônia e participar do movimento de resistência na França, chegou a Auschwitz depois de breve passagem em outros campos menores, portanto, em um momento em que os campos de extermínio ainda estavam sendo constituídos, no que viria a ser a industrialização das mortes: as câmaras de gás e os fornos crematórios. Em certo sentido, a "solução final" (HILBERG, 1996), a execução do plano de eliminação física dos judeus, ainda estava em fase de organização; no caso de Komski, uma vítima polonesa católica, um preso político (designado pelo triângulo vermelho imposto aos prisioneiros na roupa característica de Auschwitz), a foto é feita nesse momento do início dos campos de execução. 
o modelo de despersonalização nazista. ${ }^{8}$ A cadeia de efeitos (registro lateral, imagem frontal, três quartos) imprime uma condição narrativa que tem a intenção de insistir sobre o vínculo entre fotografia e hierarquização. Nas três fotos sucessivas, pode-se observar o número (564) de identificação na primeira imagem, além da roupa característica, os cabelos raspados rente ao crânio e a instrução normativa da estética fotográfica. Na fotografia de identificação, é possível ver o sistema tipológico: a imagem do busto em um fundo neutro, a perspectiva que evoca um contexto frenológico, a representação visual que aspira enfatizar um programa de hierarquia racial baseada em uma antropologia da imagem negativa.

Figura 3: Jan Komski

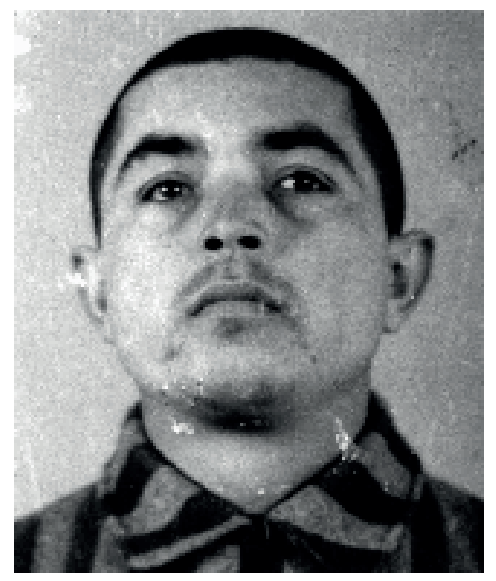

Komski é identificado com o número abjeto e o nome do campo de concentração/extermínio. Seu rosto em perfil é capturado em uma imagem rígida, com a parte de trás do crânio pousado sobre o metal que apoia a cabeça, em posição ereta. Na segunda imagem, é possível enxergar a roupa característica - aparentemente mais nova e mais ajustada ao corpo em relação à vestimenta de Czeslawa -, o triângulo vermelho que

8 Após a guerra, viveu em campos de refugiados e migrou para os Estados Unidos em 1949, já casado (com outra sobrevivente de Auschwitz). Desenvolveu seu trabalho de pintor e gravurista, com várias imagens dos campos de concentração, até sua morte, em Arlington (Estados Unidos), no ano de 2002. 
designa a posição como preso político e estava reservado aos dissidentes, o rosto em posição frontal (que não olha a câmera).

A perspectiva direta do enquadramento incide sobre o rosto jovem de Komski, com 25 anos na primeira detenção, e revela um mesmo contexto de captura. Sua expressão é confiante e serena nas três imagens, lida em um prisioneiro que já se engajava na resistência contra o nazismo. A composição literal, não obstante, evoca uma conotação fenomenológica que está, em um primeiro momento, inadvertida na narrativa das três imagens. ${ }^{9}$

Komski não olha a câmera em nenhum momento, e a posição da cabeça está levemente para cima, com o queixo para o alto, os lábios fechados, o corpo aparentemente bem nutrido. O olhar é desafiante, conciso, seguro. Mesmo com a didática frenológica, a arquetipologia negativa não consegue reduzir os signos faciais a uma expressão de desencanto, de medo, de contenção que seria a prova da culpabilidade (racial e desviante).

A interação entre o sujeito retratado e sua postura de altivez rompe, nesse caso, com a expectativa de marginalidade do sistema fotográfico. A foto é invasiva, mas a posição-testemunha do busto de Komski parece manter um equilíbrio entre o ato de despersonalização e a resistência contra a linguagem simbólica agressiva (transformação de sujeitos em coisas, intenção realística, pretensão documental baseada em um atlas da hierarquia raciológica).

A fórmula negativa - fotografias como veículo da hostilização - reitera aqui a relação de contágio da imagem: as três séries almejam a essencialidade destinatária da representação visual, lida como fiel ao processo de verossimilhança que tem o sentido de instruir (marcar, descrever, didatizar) mais facilmente uma tipologia ideal dos "rostos raciais" apreendidos. Em que pese a figura retratada, o tríptico fotográfico segue

9 É importante considerar que, no caso de Komski, um "rosto de preso político polonês" em meio a múltiplos outros rostos de dissidentes políticos, um dos efeitos da imagem é o teor de politização da vítima, que será usado na exposição no contexto de nacionalização do holocausto por parte da Polônia. 
o padrão similar que Wilhem Brasse havia de seguir, especialmente em relação à perspectiva da antropologização ideária. ${ }^{10}$

No caso de Komski, a terceira imagem também é a que carrega maiores elementos de mise-en-scène visual. Uma boina é utilizada para perspectivar a construção do que seria a pessoa parcialmente protegida por um elemento cênico. A ênfase no efeito físico da imagem aspira a uma prestação composicional que tenta alegorizar o que é uma característica da foto em sua dimensão mais contemplativa e referente. Revela-se a pessoa e o estado como prisioneiro, mas essa relação não é, apesar das características da fotografia de identificação, embrutecida. Diferentemente das duas primeiras fotografias, a composição encerra, até certo ponto, uma perspectiva emocional que designa uma espécie de força icônica recontextualizada. O estatuto fotográfico (fotografia de identificação) é desestabilizado pela perspectiva da diagonalidade da pose. Komski é fotografado dando ênfase ao perfil direito do rosto, no qual incide a valorização plástica no efeito da luz focal. Essa ênfase da angularidade da cena refrata o caráter documental da fotografia de identificação e revela uma experiência de corporeidade que não estava tão firmemente enunciada nas duas primeiras perspectivas. ${ }^{11}$

10 Baseada nos estudos do desvio na antropologia física de Cesare Lombroso (HORN, 1995), essa perspectiva buscava redimir o corpo retratado à ideia racializada de "malformação", tanto anatômica quanto moral (sic).

11 Isso posto, é possível observar que, provavelmente, o momento da captura era célere e a pressa não permitia o ajuste característico da antropometrização com rigor, deixando mais espaço para o gesto da captura em um traço de subjetivação. 
130 DO INDIVÍDUO DE REFERÊNCIA AO CONSUMO VISUAL

Figura 4: fotografia aumentada de Komski (fundo)

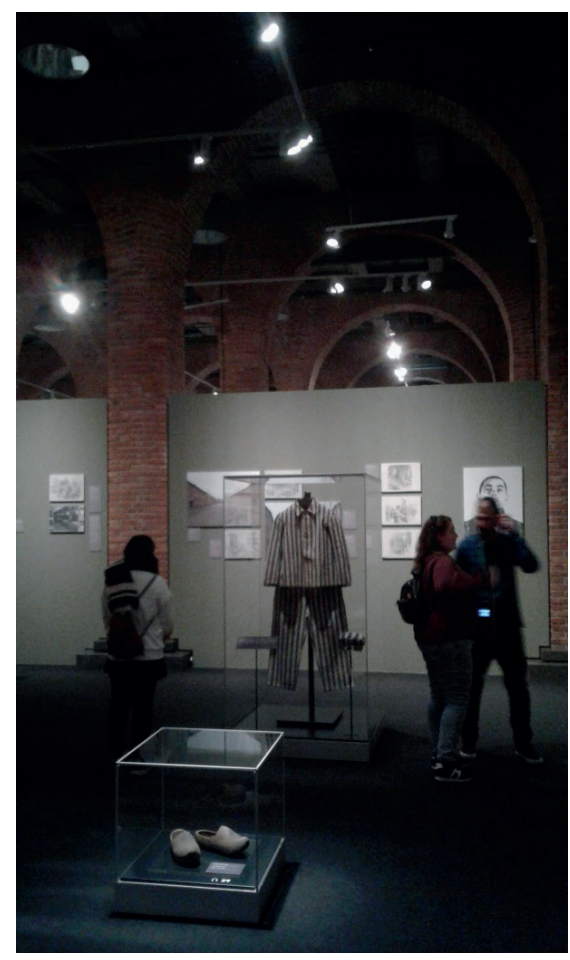

Quando a diagonalidade é enfatizada, a intencionalidade do enunciador deixa transparecer a experiência de ruptura que está contida em um ato postural que rejeita a condição de assujeitamento. $\mathrm{O}$ uso da boina e o ângulo facial, os olhos para cima, os lábios cerrados, imprimem uma credibilidade do testemunho que se quer notar, que se quer fazer.

Em certo sentido, a última parte do tríptico encerra uma desestabilização do estereótipo e "deforma" a (in)coerência da perspectiva documental, decompondo o estatuto da fotografia de identificação. $\mathrm{O}$ imaginário pode fluir mais facilmente questionando, assim, o substrato fotográfico e o gênero redutor. A inscrição em outra possibilidade interpretativa/argumentativa chama atenção por permitir um efeito de sentido e de presença (GUMBRECHT, 2010) que enlaça a dualidade do fotográfico a uma densificação plástica da imagem. Semelhante às 
fotos concebidas na perspectiva artística (galeria de arte, museu, instalações, posturais etc.), onde o trabalho do fotógrafo é mais sentido e evidente, a terceira imagem concreta uma situação estético-estésica que permite que o encorajamento seja o vetor expressivo contra o estatuto numérico da identificação.

A foto se torna gesto na gramática da essencialidade emocional de uma face à qual não foi permitido liberdade fisionômica. Mesmo assim, a situação de ameaça, a condição de protesto e a emersão da figura potente são catalisadas no efeito da câmera de Brasse, que, antes de marginalizar a pessoa, coloca ênfase no ator presencial.

O gesto postural, nesse caso, é uma linguagem que se faz presente na negação de uma "vergonha implícita” (AGAMBEN, 2008) que inutilizaria a vontade performática. O corpo de Komski não é carcaça porque vence a "perfectibilidade negativa" ao lidar com uma intersubjetividade que se reserva, da mesma forma que Czeslawa, para o espectador futuro. Não obstante, o tríptico formado, de modo mais superlativo, evita o clichê do programa fotográfico ao narrar o assujeitamento como um primeiro ato (ser fotografado) contra o movimento de estigmatização.

Aqui, não é o compartilhamento (em espera, em ato) que está mais destacadamente em relação. É o signo da imagem que entrelaça seu poder político ao dotar a identidade de uma funcionalidade a toda prova. O rosto vence o abuso sígnico (a roupa redutora, a escopofilia raciológica, a narrativa hierárquica) porque expressa, em um efeito duro, seguro, a falsidade do sistema.

Predominantemente, a crítica da visualidade na fotografia de Komski obriga o espectador a descobrir a relação infame que há no sistema em sua opressão e totalitarismo. O primeiro movimento fotográfico (tentativa de apagar o nome, carregar um número) é desconstruído na ação postural. A presença de Komski protesta contra a estrutura redutora-fotográfica e a força icônica de seu testemunho faz relatar, em um único personagem, em um único corpo dramático, a negatividade da despersonalização. Em vez de se deixar ser objeto da fotografia, Komski 
desconstrói a leitura do programa fotográfico em uma teatralidade que se abre ao processo de preservar o confronto, a determinação.

Os olhos do espectador estão sempre diretamente na imagem, da mesma forma que a interação entre fotógrafo (obrigado a fotografar) e retratado, que parecem romper com a figurabilidade expectativa. Essa símile visual - esperar a alteridade futura, propositiva - (des)identifica o posado, tensionando a fotografia de identificação com a sedução do desequilíbrio artístico.

O retrato de Komski adverte para a mensagem vernacular: o autodomínio pretenso da fotografia documento é relativizado pela "impostura" da arte. Tal como escreve Rancière (2005), a "indefinição de fronteiras" própria ao domínio artístico, nesses termos, possibilita que as potências de significação estejam correlatamente associadas ao "evento próximo", que é sempre uma alteridade a esperar.

Isso é bastante significativo no retrato de Komski, pois a determinância da fotografia de identificação, com seu enquadramento rígido, fundo neutro e estrutura de destaque face-busto, não delimita uma perda em anonimidade. É como se a funcionalidade fosse vencida pela posição em cena, que busca o retrato e a preservação da identidade. Semelhante estrutura tem suas desvantagens, como escreve Sanchez-Biosca (2017), porque aquilo que rodeia a imagem é o espectro do assassinato, da decisão enunciatária de fotografar para aniquilar (para guardar o registro em uma perpetuidade assassina).

As características da enunciação fixadas com o objetivo de transmitir uma arquetipologia negativa (circunstâncias forçadas, imaginário redutor, visão antissemita) são retidas pelo acontecimento cênico, que nega a sensação de normalidade. Insere na imagem uma potência de identificação coreografada nos mínimos detalhes e rompe com a "domesticação" do programa fotográfico ao destacar as "impurezas" (SANCHEZ-BIOSCA, 2017) da representação.

É justamente a fotografia como condição futura de consumo visual que interessa ao fotógrafo. Nesse sentido, sua luta secreta é para que ela não se torne arquivo, para que não se perca nas conveniências dos 
perpetradores. Nos termos dessa relação, a fotografia só pode ser uma potência investida por uma vontade de adjudicar uma identidade não tipificada, não desatada da posição imprescindível do ato de lembrar. Obstinada com sua representação, o tríptico desenvolve uma sensação de latência que resguarda a posição de espera. Indefectivelmente temos, ali, uma cena. ${ }^{12}$

O ato fotográfico (DUBOIS, 1993), no caso de Brasse, é necessariamente uma perspectiva da memória que registra um testemunho diáfano, posicionado na enunciação sub-reptícia. A perspectiva será sempre a de negar a coisificação redutora e redundante a partir de um jogo com a relação composicional pré-fixada e a significação nos detalhes. Olhando para dentro da imagem, é sentido seu ocultamento: uma gestualidade contida, uma insuperabilidade do rosto, uma identificação com o porvir.

\section{Inserção na arte em busca do retrato}

Figura 5 Fotografias de Thomas Ruff

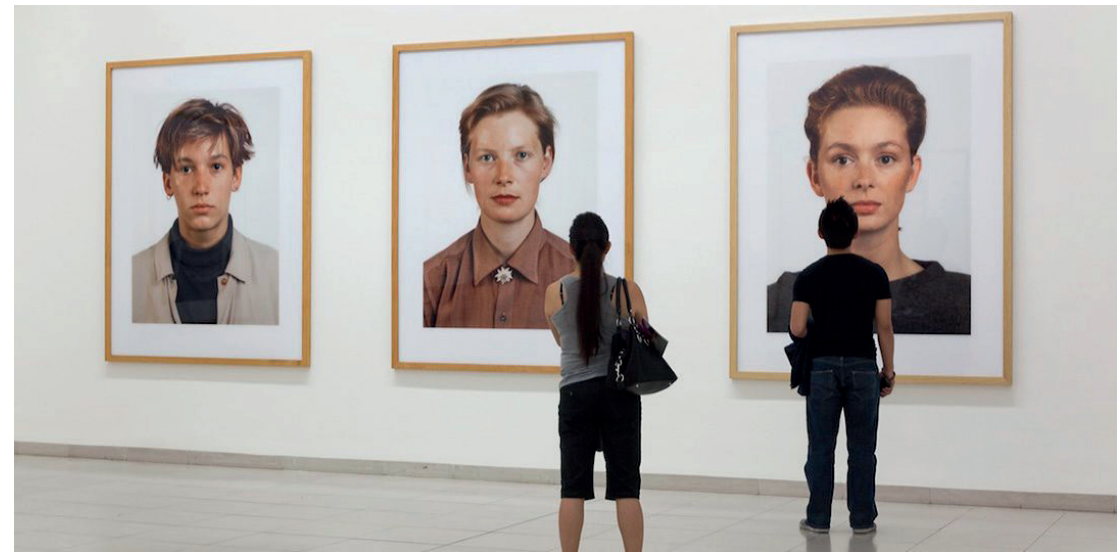

12 Emancipadamente, nos envolvemos com um testemunho ainda a ser dito, ainda a ser rastreado, exposto. 
Quando a fotografia de Jan Komski é ampliada em uma instalação artística sobre Auschwitz, ${ }^{13}$ o efeito é particularmente inquietante: a fotografia ganha espaço cênico (exposta em uma galeria de arte, aumenta as possibilidades de interpretação), perspectiva ocular (diagramada na potencialidade da foto, em tamanho exagerado), situação de enfoque (vista sem a percepção da perspectiva da rigidez da fotografia de identificação, deslocada do tríptico narrativo).

Na fenomenologia da exposição, ${ }^{14}$ a presença de Komski é ainda mais desconcertante. Como no trabalho de Thomas Ruff, fotógrafo alemão contemporâneo (nascido em 1958) que utiliza o modelo das fotografias de identificação para conceber retrato e representação, a imagem aumentada do pintor é um "texto visual" que engendra uma essencialidade dramática. A foto ampliada é a segunda do tríptico narrativo feita por Wilhem Brasse e o tom neutro, o fundo apagado e a iluminação parcial são desmontados em uma tensão entre o arquivo e a condição artística. Sob a chancela da arte, na parede de uma galeria, de uma instalação, a expressividade acentuada valoriza a perspectiva da experiência física do retrato. Komski é figurativizado em uma proporcionalidade dissonante, que alegoriza a identidade em uma sensação pictórica que coloca ainda mais em xeque o conteúdo objetualista da fotografia documental. Em certa dimensão hiperbolizada, o envolvimento emocional com a foto é maior e a sensação de proximidade se torna mais clara, estabelecida no trânsito museístico, que assume uma possibilidade de lançar um olhar mais flexível no enquadramento.

13 A instalação Auschwitz, no hace mucho, no muy lejos, aberta ao público de dezembro de 2017 a junho de 2018 na cidade de Madri, Espanha, é uma exposição monográfica sobre o campo de extermínio organizada pela primeira vez em relação à dimensão das peças, reprodução dos objetos e testemunhos.

14 A apresentação itinerante enfatiza as várias materialidades do campo: objetos, peças de procedência de várias entidades, museus e instituições, materiais audiovisuais, fotográficos, documentos, cartas, arte gráfica etc. 
Figura 6 Fotografias de Thomas Ruff

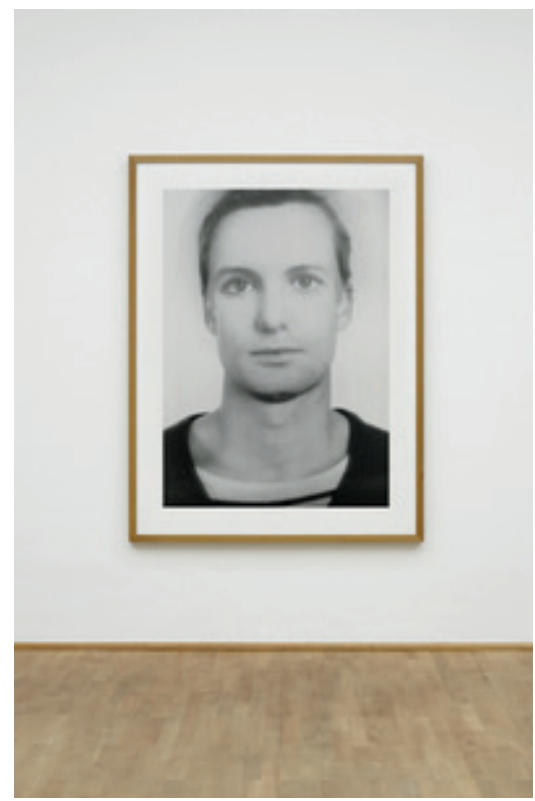

Na narrativa da instalação, que busca, paralelamente, trazer para o presente o horror do maior campo de morte da Segunda Guerra, a figura aumentada de Komski se desprende do conceito da fotografia de identificação para abraçar um jogo circulacional próprio das instalações de arte. Entre os objetos do campo, as outras fotografias e a discursividade da proposta, valoriza o engajamento perceptivo da imagem. Semelhante às fotos realizadas por Ruff nas décadas de 1980 e $1990,{ }^{15}$ a imagem de Komski recebe a valorização da luz focal e os detalhes da fisionomia podem ser mais intensivamente presenciados. ${ }^{16} \mathrm{Com}$ a perspectiva da exibição, em tempos de negacionismo e sensação de distanciamento histórico do Holocausto, a figura de Komski é alimentada por uma

15 Os primeiros retratos foram em preto e branco e apenas em uma segunda fase, alguns anos depois, Ruff começou a ampliar (mais de dois metros) as fotografias realizadas em cor, com os rostos de pessoas geralmente instruídas para posar na visão frontal e com a perspectiva da foto de identificação.

16 A monumentalidade dos retratos, segundo Koetzle (2011), atingia uma escala figurativa em que a perspectiva humana transmitia uma sensação ao mesmo tempo de intensidade da presença e (des)identificação fotográfica. 
condição de presença que indelevelmente está na impossibilidade de refutar o olhar sobre seu rosto, agigantado em proporções. ${ }^{17}$

$\mathrm{Na}$ sala de exibição, os elementos contextuais perdem referência, em que pese a fotografia do pintor já ser exibida antes, no formato tradicional. A foto pode ser vista em diferentes ângulos e jogos de perspectivas: entre as vitrines e os objetos, com nuanças lúmicas, em interações múltiplas nas posições da sala. Tal efeito é discursivamente uma possibilidade de ampliar o jogo cênico, e o engajamento com os objetos, a partir disso, transforma a imagem em uma materialidade sobrevivente, densificada, plástica.

É importante notar que, na perspectiva da instalação, que tem a intenção de explorar as representações históricas junto às condições museísticas - em um lugar comumente utilizado para exposições de arte -, o processo de abordagem da construção da fotografia se desenvolve entre o histórico e o figurativo.

O retrato de Komski é exibido em seu signo diferenciador (rosto constrito, os lábios crispados, o olhar para longe). Mas a inexpressividade e o tom sério são ambivalentemente reposicionados pelo engajamento artístico, que adjudica o valor arquivístico da imagem ao mesmo tempo que a desprende, ainda mais, da característica de fotografia de identificação.

Nesse sentido, a instrução documental é relativizada de forma mais intensa diante do predomínio da dramaticidade. Pode-se perceber uma evocação da presença com uma visualidade que interage com o espectador, em certo sentido, no plano da expressão, salvaguardando seu olhar dirigido ao infinito.

O real, aqui, parece ter sido transubstanciado em uma noção de assemelhamento (com a ênfase no dispositivo) e verte para a imagem uma circulação pictorializada, que torna a ancoragem do documento ainda menos perceptível. Não obstante, a fotografia de Komski é reposicionada

17 É interessante pontuar que a "fisicalidade renovada da imagem" tem a ver também com a organização política da exposição em termos da produção do regime de disseminação visual de um rosto polonês, entre os muitos rostos que Brasse capturou, e de sua circulação como efeito da tentativa, mais recente, de nacionalização do holocausto na Polônia (a participação como vítimas e o negacionismo atual do governo polonês em relação à participação direta nos campos). 
pelo apelo artístico-cultural e o retrato ganha uma atemporalidade a toda prova.

A imagem, com o tamanho maior do que o normal, é realinhada à luz da arte. E o verdadeiro documento - a expressão constrita, o testemunho em pose, retirado da terceira imagem dos três quartos - pode fazer emergir o sentido performático que estava preso no tríptico narrativo. A relação com o ambiente museístico, nesse aspecto, engaja a fotografia em uma narrativa multilinear que tem a ver com a valorização interpretativa do retrato. O estatuto artístico e a sutil perspectiva do trabalho de Brasse são percebidos com mais intensidade. Diante da mudança de gênero, a presença do rosto de Komski, aumentado várias vezes do original, dispersa a figurabilidade disfórica do retrato de identificação e coloca a imagem em um movimento associativo. A plasticidade da presença de Komski é sentida, então, como um testemunho possível, que está em constante movimento, que é aberto ao olhar interativo.

Junto com os depoimentos audiovisuais, com as outras fotografias e objetos do campo, com as gravuras do próprio Komski, ${ }^{18}$ a imagem se livra da "perfectibilidade negativa" e emerge, com mais força, no desejo de circulação. Para além do documento, o que há de mais profícuo em sua dramaticidade minimalista é exposta em um trânsito que enfoca a possibilidade de interação. Ausente no tríptico em um olhar mais distraído, a fotografia aumentada se abre mais para a figuratividade performática, interacional, expressiva. Questionando o gênero documental, a foto de Komski instiga uma necessidade polifônica de saber olhar, de conhecer a biografia mais intensamente. E assim, na dimensão da instalação, Komski pode ser visto sob diferentes ângulos aproximativos, mas não pode ser rejeitada sua presença inexorável, sua liminaridade impactante.

Como nos retratos de Ruff, o rosto do pintor está sempre entre a ambivalência da arte (BOURDIEU, 1996) e a particularidade do biográfico. Ao observá-lo no jogo composicional da instalação sobre Auschwitz,

18 Komski, após a liberação dos campos em 1945, migrou aos Estados Unidos, desenvolvendo trabalhos gráficos sobre a vida nos campos. Foi desenhista no jornal The Washington Post e desenvolveu imagens sobre o Holocausto. 
junto a suas gravuras sobre a vida no campo, a construção parece sugerir, de diversas maneiras, a qualidade perceptiva da imagem de Komski imediatamente liberta do tríptico, valorizando-o como pintor, como sobrevivente, como artista enunciatário. ${ }^{19}$

A linguagem pessoal, portanto, pode ser reforçada no tratamento cultural e o referencial físico parece perspectivar a noção de que o rosto se emancipa de seu passado - do tríptico condicionante, da dimensão histórica. O poder elucidativo da imagem tem a ver com a nova possibilidade de circulação. Diante da fenomenologia da exposição, em um novo consumo visual, o retrato de grande tamanho de Komski se associa ao olhar transitivo, que afeta, inquire, se abre na montagem da exposição.

Essa recontextualização pela arte, como nos trabalhos de Ruff, ${ }^{20}$ é fundamental, pois, em vez de uma perspectiva forçada pela história, a posição de presença veicula gestos do olhar. A fotografia se torna imagem resistente, que se interliga ao movimento de aparição (LÉVINAS, 2010) da face. Ela não é apenas mais um resíduo da composição narrativa enquanto um testemunho condicionado ao contexto histórico. Passa a ser permeável ao elemento de deixar ser capturada, de poder ser vista com a linguagem predisposta, em acolhimento. Isso significa que o rosto de Komski, na instalação, emerge com uma relacionalidade possível, aberta.

A gênese documental se registra em outra substância que compõe as duas formas - os dois desejos - de veiculação do documento: a fenomenologia da foto histórica (documento) com a que a faz circular (exposição e consumo visual). O rosto épico de Komski escrutina, assim, na singularização do modelo, a possibilidade de relação. Mas sem fazer com que o modo de enunciar seja proporcionado pela dimensão

19 Numa exposição como Auschwitz, no hace mucho, no muy lejos, o trabalho das imagens e dos objetos não é apenas interceder para uma correta consciência do repúdio com que o acontecimento deve ser visto. É se dirigir ao lugar do espectador, atingido pessoalmente pelos portadores atrás dos objetos.

20 "Debido al tamaño se daban cuenta de que aquello no era una persona, sino una gran fotografía. Esto supuso prácticamente una liberación y es una técnica que he utilizado en casi todas las series que vinieron después..." (BOYM, 2003). 
referencial da marca histórica. É a atemporalidade do rosto em grandes proporções, nesse aspecto, que desfaz a centralidade da narrativa documental. Ela convoca o sentido de presença e de afetos para a relação do fotografado com aquele que o olha. Nesse sentido, o engajamento na circularidade promovida pelo efeito disruptivo de aumento do tamanho e a descontextualização do tríptico abre o gesto para seu desmembramento, para sua rememoração. É o valor da vida, é o signo da sobrevivência, cada vez mais, que está em evidência.

A imagem, portanto, se torna um elemento de inquietude que transporta o documento, mas intensifica o testemunho e sua concentração. Contudo, não é refém da narrativa típica da fotografia de identificação. Deixa o corpo, o rosto, ser presença. Na medida em que depende mais do fluxo, das relações entre a imagem e sua geografia de exposição, já não tem a ver, unilateralmente, com a significação histórica. Tem seu desdobramento naquilo que figura, que perscruta, que se move para os olhos outros, com desejo de olhar.

\section{Considerações finais}

$\mathrm{Na}$ fotografia de Jan Komski realizada por Brasse em um momento anterior à Segunda Guerra, no início dos campos, a ênfase recai sobre o gesto postural (enfrentamento, não rendição, performance altiva). ${ }^{21} \mathrm{~A}$ ontologia do retrato se perfila numa intersubjetividade entre fotógrafo e fotografado. Uma ação visual produz um estado de sinonímia da foto com a imagem, gerando resistência, destinando-a ao futuro.

Nesse caso, o tríptico conserva uma luta contra a despersonalização característica desse estilo de fotografia-limite. A composição de Brasse reescreve os elementos de iconicidade em uma actância postural que relativiza a "impostura" da fotografia de identificação. Perceptível sobretudo na terceira imagem, na perspectiva em perfil, a foto se aproxima

21 Destacando, novamente, a particularidade da exposição em relação a dois contextos: o distanciamento histórico com os acontecimentos (fonte de preocupação, com o aumento do negacionismo e revisionismo atual) e a necessidade de fazer circular diversamente as imagens históricas. 
mais da força mítica das imagens de um guerrilheiro ou de líder valente. No fim, o que se constrói em termos de mise-en-scène visual é uma ênfase no efeito físico da imagem. Que, ao mesmo tempo, conserva uma condição concentracionária e uma ontologia da pose (indestrutível) do retratado.

No efeito de uma instalação sobre o campo de morte, o rosto aumentado de tamanho e extraído do contexto que o faz prisioneiro do estilo about-to-die (SANCHEZ-BIOSCA, 2017) revela uma nova materialidade associativa. Semelhante ao trabalho do fotógrafo Thomas Ruff, que aumenta a perspectiva dos retratos para criar um ato de dilatação presencial, a face de Komski (extraída da terceira foto) sublinha um desejo de indestrutibilidade.

O gesto da arte (DE DUVE, 2009) está presente na obrigação de olhar. Impõe um silêncio que, na fenomenologia da exposição, torna a face uma potência ética (LÉVINAS, 2010). Ou um dizer sobre a alteridade impedida naquele momento. A foto de Komski, em proporções monumentais, cria um estranho vínculo com a implicação do espectador, expondo mais a fundo o trânsito entre a gênese histórica e a circulação artística. Nesses termos, é a rubrica da arte que essencializa a fisicalidade da imagem. Seu ato de presença, sua direção de sentido é menos condicionada pela impressão narrativa do estatuto fotográfico inicial. O desejo de ser coreografada com os objetos da exposição e a durabilidade do olhar na sensação museística, não obstante, confirma o apêndice da imagem: seu sentido disponível tem a ver com a experiência de ver. Nesse aspecto, é inevitável olhar mais.

Quando se tornam consumo visual, com o afastamento histórico, sofrem o risco de se perder na banalização e na expectativa redentora: não há final feliz em Auschwitz, como lembra Agamben (2008). Mas também, com a ação da arte (cor e tamanho), as fotografias recebem uma possibilidade de aumentar a percepção física da presença. O apaziguamento visual, o conforto histórico do preto e branco (pertence ao passado) é desfeito pelo ato de hibridismo e circulação. A possibilidade do olhar, nesse caso, sua promessa e sua convocação, são mais 
disponíveis em uma alteridade que não pôde estar ou que esteve sob o encaminhamento da ameaça.

A sequência fotográfica realizada por Wilhem Brasse, o fotógrafo prisioneiro de Auschwitz, em natureza efetiva, mas em ato inacabado, reacende o incômodo do não ter visto a foto. Quando ela "queimava", quando ela "ardia". Modificadas pelo efeito artístico, respiram novamente. Por transformação, se fazem, enfim, notar. Desde a abertura artística, desencadeiam o que estava em gênese no trabalho do fotógrafo.

Como se abríssemos, outra vez, sua saga política. Em um álbum de memória que não pode deixar de lembrar. Um gesto intenso, uma relacionalidade pronunciada.

\section{Referências}

AGAMBEn, G. O que resta de Auschwitz. São Paulo: Boitempo, 2008.

BOURDIEU, P. As regras da arte: gênese e estrutura do campo literário. São Paulo: Companhia das Letras, 1996.

BOYM, P. Thomas Ruff: 1979 to the present. Nova York: D.A.P Art Publishers, 2003.

DE DUVE, Thierry. "A Arte diante do Mal Radical”. Ars. V. 7, n. 13, 2009.

DUBOIS, P. O ato fotográfico e outros ensaios. Campinas: Papirus, 1993.

EDWARDS, E. La photographie ou la construction de l'image de l'autre. In: BANCEL, N.; BLANCHARD, P.; BOËTSCH, G.; DEROO, É.; LEMAIRE, S. (Orgs.). Zoos humains. Au temps des exhibitions humaines. La Découverte, 2004.

ENGELMANN, R. Der fotograf von Auschwitz. Berlim: CBT, 2015.

GUMBRECHT, H. Produção de presença: o que o sentido não consegue transmitir. Rio de Janeiro: Contraponto, 2010.

HILBERG, R. La politique de la mémoire. Paris: Gallimard, 1996.

HORN, D. This norm which is not one: reading the female body in Lombroso's anthropology. In: TERRY, J.; URLA, J. (Orgs.). Deviant bodies. Bloomington: Indiana University Press, 1995. p. 70-93.

KOETZLE, H. Fotógrafo de la A a la Z. Madri: Taschen, 2011.

LÉVINAS, E. Ética e infinito. Lisboa: Edições 70, 2010.

RANCIÈRE, J. A partilha do sensível. São Paulo: Editora 34, 2005. 
RASSOOL, C.; HAYES, P. Do trabalho de campo à exposição do império: a viagem da bosquímana Khanako pela África do Sul (1936-1937). In: MAGGIE, Y.; REZENDE, C. (Orgs.). Raça como retórica. Rio de Janeiro: Civilização Brasileira, 2001.

SANCHEZ-BIOSCA, V. Miradas criminales, ojos de víctima: imágenes de la aflicción en Camboya. Buenos Aires: Prometeo, 2017.

ZELIZER, B. Remembering to forget: Holocaust memory through the camera's eye. Chicago: University of Chicago Press, 1998.

\section{Sobre 0 autor}

Rafael Tassi Teixeira - Doutor em Sociologia pela Universidad Complutense de Madrid (UCM). Pós-doutor em Estudos da Imagem (Universitat Autònoma de Barcelona, UAB). Vice-coordenador do Programa de Pós-graduação em Comunicação e Linguagens da Universidade Tuiuti do Paraná (PPGCOM/ UTP). Professor adjunto da Unespar, campus Curitiba II (Sociologia da Arte, Estudos Culturais, Antropologia Audiovisual). Líder do grupo de pesquisa (CNPq) Desdobramentos Simbólicos do Espaço Urbano nas Narrativas Audiovisuais (Grudes). Seus estudos abrangem a área das mediações culturais, estudos diaspóricos, cinema ibero-americano, antropologia audiovisual, fotografia e memória etc.

Data de submissão: 19/1 1/2018

Data de aceite: 27/02/2019 